\title{
BIBLIOTECAS POPULARES EN CANARIAS: LA BIBLIOTECA DE EL OBRERO
}

\author{
por MANUEL DE PAZ SÁNCHEZ, \\ VALERIA AGUIAR BOBET, \\ ÁNGEL DÁMASO LUIS LEÓN \\ (Universidad de La Laguna)
}

\begin{abstract}
Resumen
En este trabajo se recoge una amplia muestra de libros de la biblioteca popular de la Asociación Obrera de Canarias (Santa Cruz de Tenerife, Islas Canarias). Se trata de una biblioteca reconstruida a base de las referencias publicadas en el órgano periodístico de la Asociación, es decir, el periódico El Obrero. Mediante este trabajo nos aproximamos a las aficiones literarias y culturales, en general, de un colectivo social influido por el movimiento anarquista de principios del siglo XX, que fue importante en España y en Canarias, así como también en la América española. El inventario permite identificar diversas obras literarias de novelitas franceses y rusos, principalmente, pero también algunos tratados pedagógicos y esotéricos, como son los estudios sobre masonería, espiritismo, etc. Entendemos que este tipo de inventarios puede resultar útil para el estudio de diversos aspectos ideológicos, políticos y culturales de la Asociación Obrera de Canarias, que fue la primera entidad obrera de cierta importancia que existió en el Archipiélago.
\end{abstract}

Palabras clave: Canarias; historia cultural; bibliotecas populares y obreras.

\section{Libraries in Canary: The Library of El Obrero}

\begin{abstract}
This work includes a large sample of books from the popular library of the Canary Workers Association (Santa Cruz de Tenerife, Canary Islands). It is a reconstructed library based on the references published in the journalistic body of the Association, that is, the newspaper El Obrero. Through this work we approach literary and cultural hobbies, in general, of a social collective influenced by the anarchist movement of the early twentieth century, which was important in Spain and the Canary Islands, as well as in Spanish America. The inventory allows to identify various literary works of French and Russian novels, mainly, but also some pedagogical and esoteric treatises, such as studies on Freemasonry, spiritualism, etc. We understand that this type of inventory can be useful for the study of various ideological, political and cultural aspects of the Canary Islands Workers'Association, which was the first workers' entity of blind importance that existed in the Archipelago.
\end{abstract}

Keywords: Canaries; cultural history; popular and working libraries. 
¿Existen las bibliotecas populares o, más bien, tendríamos que hablar de bibliotecas sin más, aunque destinadas a un uso decididamente popular? Esta parece ser la finalidad esencial de la biblioteca de la Asociación Obrera de Canarias, ${ }^{1}$ que publicaba su propio semanario, El Obrero, y que gracias a la munificencia de sus socios y simpatizantes pudo hacerse con una biblioteca cuyos listados de fondos se publicaron, para orgullo y satisfacción general, en varias entregas en el periódico de la propia entidad.

La educación, se decía, era la palanca que podía cambiar al mundo. Por eso, la creación de bibliotecas se convirtió en una necesidad perentoria y, paralelamente, en un gesto de autosatisfacción, de misión cumplida, de estar, en fin, en el camino correcto.

Así se deduce del texto publicado en el número del 19 de abril de 1902, en el que se dio cuenta de la cesión de sendos lotes de libros por los ministerios de Instrucción y de Agricultura, "para los obreros en general", a petición del gremio de tipógrafos y gracias a la mediación de los representantes en las Cortes de Tenerife (marqueses de Casa-Laiglesia y Villasegura):

Desde que el organismo que en la prensa representamos cimentose fuertemente y llevó a sus filas entusiastas adeptos para las luchas societarias, y conquistó el respeto de sus propios enemigos, dejábase sentir extraordinariamente la gran necesidad de medios que ilustraran al obrero, arrancándolos de las fauces del vicio que engendra todos los males, para encaminarlos por el noble sendero de la instrucción y de la laboriosidad, de la inteligencia y del trabajo. ${ }^{2}$

Gracias a la creación de bibliotecas, concluía el suelto de referencia, se podría contribuir de manera decidida a la instrucción de las clases trabajadoras, y:

Si los obreros todos fueran instruidos, y por lo tanto comprendieran lo que la unión significa, el lazo de la tiranía y de la miseria que le oprime, hubiera desaparecido, avasallando a los malditos explotadores que se oponen al bienestar y la emancipación del trabajador.

Pocos meses después, el vocero de la entidad hacía pública su satisfacción por el hecho de que, a partir del núcleo inicial de la biblioteca donada por el Gobierno, muchos compañeros del centro obrero se habían sumado al proyecto donando "gran número de obras de notable valor científico y literario", en concreto más de doscientos volúmenes. Se comenzó, a partir de entonces, a publicar los títulos en el periódico, así como los nombres de los donantes, entre los que ocupaba un lugar muy destacado José Cabrera Díaz, ${ }^{3}$ periodista de fuste, anarquista, masón y un tanto demagogo que, en septiembre de 1902, fue designado para dirigir a la publicación vocera de la organización obrera, en sustitución de Policarpo Expósito. Así se deduce del listado de benefactores publicado:

1 Francisco GALVÁN FERNÁNDEZ, Burgueses y obreros en Canarias: (del S. XIX al XX), La Laguna 1986; Francisco GALVÁN FERNÁNDEZ y Luis MARTÍNEZ DE AZAGRA, Trabajos socioeconómicos: Canarias a finales del siglo XIX, Santa Cruz de Tenerife 1994.

"Dos bibliotecas", El Obrero, 19 de marzo de 1902, p. 2.

"Nuestra biblioteca", El Obrero, 28 de junio de 1902, p. 3. 
José Cabrera Díaz

Carlos Córdoba

Manuel A. de la Rosa

Manuel S. Espinosa

Manuel Padrón Pérez

Cosme Castellano

Manuel Déniz

Víctor González Machín

Ismael Baucell

Pedro M. García

Gaspar Cruz Brito

Juan Castrillo

Miguel Báez

Romualdo Real

Daniel Cruz

Antonio Rodríguez

Antonio Encinoso

Agustín Aguiar

Federico González

Alfredo J. Boligán

Celestino González

Juan Arnay

Juan Benítez
162 volúmenes

32 Ídem

22 Ídem

20 Ídem

17 Ídem

12 Ídem

7 Ídem

6 Ídem

5 Ídem

5 Ídem

5 Ídem

4 Ídem

2 Ídem

2 Ídem

2 Ídem

2 Ídem

2 Ídem

2 Ídem

1 Ídem

1 Ídem

1 Ídem

1 Ídem

1 Ídem ${ }^{4}$

Opinaba el redactor del periódico, en este mismo contexto, que el aprendizaje $\mathrm{y}$, en consecuencia, el cambio de mentalidad y el mejoramiento de la clase obrera gracias a su ilustración mediante la creación de bibliotecas, iba a ser lento y difícil, pero que algún día se verían los frutos de este esfuerzo inicial. Se hacía necesaria, por tanto, una correcta elección de las obras, "teniendo en cuenta las circunstancias de la clase trabajadora", y, en tal sentido, se hacían más necesarios:

Libros de sociología, que ilustren a los obreros acerca de las trascendentales cuestiones que en el campo social y filosófico se debaten y de los graves problemas que hoy preocupan a todas las inteligencias; libros de geografía, viajes y mapas; de educación, gimnástica, higiene y medicina doméstica; tratados de agricultura, industria, artes y oficios; de lengua castellana, de fisiología e historia natural; y de otras materias instructivas y agradables, deben constituir el fondo de las nuevas bibliotecas y muy especialmente de la nuestra [...].

Había una especie de fe, un sentimiento mágico y, en ocasiones, ingenuo de la acción cuasi sacra del libro como tal, que, en efecto, podría transformar radicalmente la vida de un lector privilegiado.

4 “Una buena obra", El Obrero, 20 de septiembre de 1902, p. 3. 
¡Cuántas veces un libro cualquiera en manos de un niño o de un adulto da a conocer aptitudes especiales, que sin este medio quedarían ignoradas! Esas excursiones de la inteligencia por variados asuntos y materias es una tentativa, un hecho admirable para descubrir la vocación de cada ingenio, punto el más trascendental en la práctica de la enseñanza, en la elección de carrera, decisión de la suerte del individuo y de la familia.

En resumen, en nuestro sentir, la Biblioteca ha de dar frutos exquisitos para la educación de los compañeros. Serán lentos, lentísimos, porque así procede la naturaleza en sus grandes obras, y así se verifican también las hondas transformaciones sociales; mas es indispensable echar el cimiento, si algún día se ha de completar el edificio. ${ }^{5}$

En otra de sus entregas, El Obrero había llamado la atención sobre la necesidad de potenciar la biblioteca de la asociación con nuevas y continuas donaciones, ya que, según se dijo, "cada época tiene sus instituciones y la que atravesamos se distingue por la fundación de bibliotecas públicas y particulares en todos los pueblos cultos". Se trataba de servir, teniendo en cuenta el precio de los libros, a los espíritus instruidos para que pudieran desarrollar su misión social y, al mismo tiempo, de dotar al lector medio de obras esenciales, útiles para "empaparse en los diversos ramos de los conocimientos humanos". ${ }^{6}$

Ahora bien, a la luz de lo que llevamos expuesto, podríamos preguntarnos, ¿es que acaso los libros de los que, en teoría, podría disponer el lector obrero interesado, en el hipotético y dudoso caso de que supiera leer, estaban al alcance de sus conocimientos o, más bien, estamos ante un gesto de los dirigentes de la asociación, con el objetivo de justificar y justificarse ante sus socios, ante la administración que había donado parte de los fondos, y, en fin, ante el público en general?

Algunos de los libros que se relacionan a continuación y que, como el resto de los que aquí se citan, se han tomado de las listas, a veces inexactas, publicadas por el rotativo obrero, nos hacen pensar en que, por el contrario, la creación de esta biblioteca tuvo, salvo raras excepciones, escasa utilidad para el colectivo obrero de Santa Cruz de Tenerife, ya que, a buen seguro, las minorías verdaderamente ilustradas y dirigentes de la asociación, tendrían otros medios para hacerse con las obras que se mencionan y, desde luego, con otras varias en la Biblioteca del Instituto Provincial $^{7}$ (en La Laguna) y en otros centros, tanto públicos (casinos, ateneos, círculos, gabinetes) como particulares (bibliotecas individuales), sin olvidar que, ayer como hoy, la mayoría de los lectores prefería consultar el periódico y adoctrinarse a través de sus concisos titulares antes que leerse a los clásicos en la materia, por lo común embrollosos y confusos, especialmente para individuos de escasa formación académica.

5 Ibidem. Véase, además, Manuel ROMERO TALLAFIGO, De libros, archivos y bibliotecas: venturas y desventuras de la escritura, Las Palmas de Gran Canaria 2008.

"Nuestra Biblioteca", El Obrero, 16 de agosto de 1902, p. 4.

Manuel DE PAZ SÁNCHEZ, La biblioteca olvidada: (los libros del Convento Franciscano de Garachico), Santa Cruz de Tenerife 2010. 
Llaman la atención, empero, algunos de los títulos que el lector interesado podrá ver a continuación. Pensemos, por ejemplo, en esa maravillosa historia de amor de la Edad Media que son las Cartas de Abelardo y Eloísa, un extraordinario poema en prosa, sobre el que se funden debates escolásticos, visiones de amor cortés y, en fin, la sublime tragedia de dos amantes que solamente se abrazan con libertad tras la muerte de Eloísa o Heloisa, cuando se afirma que el cadáver semi-momificado de Abelardo, al ver que su amada esposa iba al fin a ser enterrada a su lado, en el mismo sarcófago, extendió sus esqueléticos brazos para estrecharla, al fin, por toda la eternidad. ${ }^{8}$ Se trata, sin duda, de una historia conmovedora, una de las grandes historias de amor de la Humanidad. Ojalá los obreros de ambos sexos de la primera Asociación de trabajadores de Canarias hubiesen podido disfrutar plenamente de ella.

En el ámbito de los libros de autores canarios se cuentan algunas obras de interés, pues aparte de los escritores más conocidos como, por ejemplo, don Benito Pérez Galdós, merecen especial mención los ensayos de Miguel Villalba Hervás, Elías Zerolo y el propio Servet, es decir, Miguel B. Espinosa, cuya memoria masónica contra el jesuitismo custodiaba la Biblioteca obrera como uno de sus pequeños tesoros bibliográficos.

En efecto, el médico Miguel B. Espinosa de los Monteros Rodríguez había nacido en Guanajay (Cuba) en 1838, aunque sus progenitores procedían del Archipiélago. Fue director de La voz de Taoro (1876-1878), entre otros periódicos, pero, además, compuso poemas, pronunció conferencias, tradujo algunas obras sanitarias del francés y falleció en La Orotava en 1898. Alcanzó el grado $18^{\circ}$ del Rito Escocés Antiguo y Aceptado y ocupó, entre otros cargos, la Veneratura de la logia Taoro de la citada Villa en 1881, tras la crisis constitucional masónica que acabó con la "década prodigiosa" de la masonería en Canarias. El 18 de marzo de 1883 causó baja en el taller por plancha de quite, como era preceptivo, aunque existen indicios de que pudo retornar por algún tiempo a la actividad masónica, pero como mucho hasta finales de 1886. Espinosa de los Monteros había redactado una Memoria en 1876, con la intención de participar en un concurso que había convocado la logia Lealtad de Barcelona, precisamente con el objeto de combatir a los jesuitas, y que había merecido, en 1877, un diploma de honor. Influido por las corrientes deístas que tanto sedujeron a ciertos masones canarios, españoles y americanos de la época, el autor del opúsculo comenzaba por describir, extasiado, el valle de La Orotava, ${ }^{9}$ pues la naturaleza exuberante, según decía, había permitido a los canarios sentirse hijos de la libertad y, desde hacía pocos años, los más preclaros se integraban en las logias masónicas. "Los jesuitas -escribía- han sido mirados en esta tierra clásica de la libertad con el horror instintivo que inspiran los reptiles venenosos desconocidos por fortuna en estas amenas latitudes", aunque, en

8 Javier GONZÁLEZ ANTÓN, “El libro antiguo en Canarias”, in: Pedro Manuel Cátedra García y María Luisa López-Vidriero Abello (coord.), Separata de: El libro antiguo español: actas del Segundo Coloquio Internacional (Madrid), Salamanca 1992, pp. 241-246.

9 Manuel DE PAZ SÁNCHEZ, "El Jardín de la Virtud (La masonería como una disidencia cristiana del XIX)”, Anuario de Estudios Atlánticos 53, Las Palmas de Gran Canaria 2007, pp. 299-336. 
honor a la verdad, la congregación erigida por San Ignacio de Loyola apenas había tenido significación en Canarias y, particularmente, en Tenerife. La enseñanza de la juventud -continuaba nuestro autor-, "confiada aquí, desde el principio de su desarrollo que no data más allá de mediados del siglo pasado, a profesores hijos del país, enlazados con sus educandos por los lazos de la amistad y del parentesco ${ }^{10}$ si no tendió desde luego al franco conocimiento de los teoremas científicos y a la libre emisión del raciocinio filosófico, no se opuso, sin embargo, de una manera decidida y temeraria a las ideas de los enciclopedistas franceses, y las obras de Voltaire y de Rousseau ocupaban un lugar predilecto en las bibliotecas de la juventud estudiosa". Tras reiterar los habituales tópicos sobre los "tenebrosos" proyectos de dominio mundial por parte de la Compañía de Jesús y sus "perniciosas doctrinas" que se apoderaban del "ánimo de la juventud", pasó a responder a la pregunta fundamental del concurso, es decir, ¿qué conducta debía seguir la masonería para sobreponerse al jesuitismo?

Su respuesta recurrió una vez más a la retórica al uso:

La fuerza incontrastable de la idea buena, abriéndose paso a través de los obstáculos opuestos a su propagación y desarrollo; el convencimiento íntimo de los pueblos que iluminados por el faro esplendoroso de la instrucción, alcanzarán al fin la meta deseada; el desprestigio que en continuado crescendo va echando por tierra el deleznable edificio de la superstición y el fanatismo; la ceguedad o la locura con que Dios quiere perder a los que se empeñan en no abandonar el cetro que la ignorancia y la barbarie pusieron en sus manos; estos son los grandes, los valiosos elementos con que la Mas:. [sic, = Masonería] debe contar para sobreponerse al Jesuitismo.

Se trataba de edificar nuevos templos donde brillaría lo que definió nebulosamente como "el Delta esplendoroso de la verdad, símbolo de la sabiduría infinita y emblema augusto de la justicia eterna". Nuevos templos regidos por la fraternidad que, en la poco rigurosa opinión de algunos de los teóricos de la masonería, hundía sus raíces en un remoto pasado, cuyas raíces, como creían ingenuamente, se encontraban en las religiones primitivas ${ }^{11} \mathrm{y}$, en cierto modo, en el libro hermético de la

10 Joan BESTARD, Parentesco y modernidad, Barcelona 1998.

11 Según Guadarfía (Manuel Quintero y García, grado $18^{\circ}$ ), en un trabajo que vio la luz en el órgano de prensa de la logia Tinerfe núm. 114 de Santa Cruz de Tenerife, en febrero de 1881, los orígenes remotos de la masonería se perdían "en la noche de los tiempos", es decir, lo mismo que había manifestado el propio Andrés Cassard. Desde el punto de vista histórico-religioso, indicó, "se atribuye su cuna ya a la India, ya a la Persia, a Egipto, a Grecia, a Roma, a Salomón, a Pitágoras, a las antiguas sociedades de albañiles", y añadió: "A la India porque fue la patria del simb.: [sic, = simbolismo] y cuna del género humano. Sus legisladores Indra y Budha proclamaron a un Dios único, creador, conservador y destructor y simb.: [sic] en el triángulo, que hasta hoy se conserva en la mas.: simb.: [sic] la unidad y la trinidad. A la Persia porque Zoroastro y después Menú predicaron y enseñaron la buena doctrina y la inmortalidad del alma; que de la unidad de Dios dedujeron la unidad de las razas, y de aquí la igualdad civil que produjo la fraternidad universal y la libertad de pensar, y por último a que en su época se comenzaron las inic.: [sic] por los magos. El último proclamó tres dioses o soles [...]; o un solo Dios o sol representado bajo tres modos de acción: uno y trino. A Egipto porque allí se extendió la inic.: [sic] con todos sus misterios que son nuestros misterios y que en Osiris representaban al buen 
naturaleza, escrito sobre el dosel inmenso de la tierra desde el instante primigenio de la creación. Se trataba, en definitiva, de disputar a las huestes del "fanatismo y la intransigencia" la llave del éxito que no era otra que la de la "instrucción”, palanca poderosa que, como la de Arquímedes, se mostraba capaz por sí misma de cambiar el destino de la humanidad. Una mezcla sutil de ingenuidad historicista (orígenes mitológicos) y de confianza laicista y positivista en el futuro parecía colmar las ambiciones intelectuales de estos hombres. ${ }^{12}$

Respecto al registro general de obras no faltan, aparte de los grandes novelistas franceses y rusos, ensayos diversos relacionados con la educación (Escuela Moderna), la propia masonería y el espiritismo, fenómenos de moda durante estos años y, naturalmente, varios textos clásicos sobre el anarquismo y el anarco-comunismo, lo que, en cierto modo, constituye un indicio interesante de los aspectos ideológico-políticos de la Asociación Obrera de Canarias, integrada por las vanguardias obreras de la época en el Archipiélago.

La biblioteca continuó creciendo, gracias a las donaciones que llegaban a la redacción del periódico. Así, por ejemplo, en 1903 se recibió el folleto de Ricardo Mella, editado por la "biblioteca de El Corsario" de Valencia, La bancarrota de las creencias, que incluía el ensayo titulado El anarquismo naciente. "El folleto de Mella es digno del estudio de todos los compañeros, a quienes recomendamos mucho su lectura".

El segundo librito se titulaba Militarismo y contenía la conferencia que Ladislao Hommes había leído en la Sociedad de Albañiles de Barcelona. Además, ambas obras podían adquirirse a través del vocero tinerfeño, al precio de 10 y 5 céntimos por ejemplar, respectivamente. ${ }^{13}$

En 1904, El Obrero se hizo eco de dos nuevas publicaciones. El sindicato de E. Pouget, publicado en la colección "La Huelga General" de Barcelona; y, asimismo, Resumen de la historia de España, que se debía a la pluma de otro personaje muy singular, el canario don Nicolás Estévanez, que en este caso dio a la estampa la Escuela Moderna de la capital catalana. Todo un símbolo.

El crítico de esta última obra, tras unos breves pero contundentes elogios, manifestaba lo siguiente:

Por la lectura de este libro, pues, el niño y el adulto se despojan de la insana solidaridad de la sumisión patriótica y quedan aptos para aquella otra solidaridad humana nacional que se funda sobre la sociología. ${ }^{14}$

principio, en Isis a la luz y en Orus a la verdad. A Roma porque Numa Pompilio fue el fundador de los colegios constructores. A Salomón por el magnífico Temp.: [sic] que elevó a la Sabiduría y al Trabajo y cuya historia ya conocéis [...]", básicamente se trataba de temas rituales tomados de J. M. Ragon, al que luego vamos a referirnos.

12 Manuel DE PAZ SÁNCHEZ, "El jardín de”, pp. 299-336.

13 El Obrero, 23 de julio de 1903, p. 4.; Robert DARNTON, Edición y subversión. Literatura clandestina en el Antiguo Régimen, Madrid 2003.

14 "Notas", El Obrero, 23 de julio de 1904, p. 4. 


\section{TÍTULOS $^{15}$}

Generales $^{16}$

ABELARDO

Abelardo y Eloísa (Cartas)*

ALCAHALÍ, Barón de

Diccionario de artistas valencianos

[Diccionario biográfico de artistas valencianos / por el barón de Alcahalí, Imp. de Federico Domenech, Valencia, 1897]

\section{ALCÁZAR}

Historia de Filipinas

[Historia de los dominios españoles en Oceanía: Filipinas / por José de Alcazar. Madrid: [s.n.], 1897 (establecimiento tipográfico de El Nacional à cargo de B. A. de la Fuente). 188 pp., [1] h. de map.pleg. ,[28] h. de lám. : ils.; 21 cm]

\section{ALTAÏR}

Fundamentos de la anarquía*

La doctrina anarquista

[Fundamentos y lenguaje de la doctrina anarquista: conferencia pronunciada el $1^{\circ}$ de mayo de 1900 en el Centro Libertario / por Altaïr. Buenos Aires: Librería Sociológica, 1900. 45 pp.; 19 cm. Serie: Propaganda Libertaria]

\section{AMADOR DE LOS RÍOS}

La ermita del Cristo de la Luz [Amador de los Ríos y Fernández de Villalta, Rodrigo (1849-1917). La ermita del Santo Cristo de la Luz en Toledo: estudio arqueológico motivado por los últimos descubrimientos de febrero de 1899 / por Rodrigo Amador de los Ríos y Villalta. Madrid: [s.n.], 1899 (Imprenta de San Francisco de Sales). 43 pp, [2] h. de lám. pleg.; ils.; $19 \mathrm{~cm}]$

AMBERLEY, conde de Un ladrón de alto capote [Folletín de Nuevo Mundo. Hacía 1900, 80 pp.]

15 Donados por José Cabrera Díaz (*). Cf. El Obrero, 28 de junio de 1902, p. 3 ; 5 de julio de 1902, p. 4; 6 de septiembre de 1902, p. 4; 13 de septiembre de 1902, p. 4; 27 de septiembre de 1902, p. 4; 4 de octubre de 1902, p. 4; 11 de octubre de 1902, p. 4; 1 de noviembre de 1902, p. 4.

16 Los datos están tomados de la página web técnica del Ministerio de Cultura, y se han dejado tal como figuran en esa base de datos que es del Gobierno y que nosotros no cambiamos véase: "Patrimonio bibliográfico" [on-line]. Patrimonio Bibliográfico Español, [consultado 10 de agosto de 2019]. Accesible de: http://catalogos.mecd.es/CCPB/cgi-ccpb/abnetopac/O12444/IDc8f6f80d?ACC=101). 


\section{ANÓNIMOS}

Apuntes sobre masonería

Aranceles de Aduanas de Cuba

Biblioteca del marqués de la Romana

Colección legislativa de $1^{\mathrm{a}}$ enseñanza.

Congresos de Albañiles

XIV Congreso de Medicina

Cristo y los obreros.- $\mathrm{X}^{*}$

Cristo y los obreros.- Apostolado.

En defensa de los militares

Diccionario enciclopédico

Exposición del Banco

Fruta verde

Guía del inmigrante en el Perú

Juegos florales

Leyes sobre agricultura

Leyes de accidentes del trabajo, etc.*

Leyes sobre instrucción pública

La luz masónica.- L. T. R.*

La masonería.- X*

Lista de abogados

Máximas inmorales de los jesuitas

Memoria de la Cruz Roja

El nuevo socialismo.- Un obrero*

Ofrenda al libertador

Para uso del pueblo

Parnaso español

Un príncipe perdido

El progreso humano.- $\mathrm{X}^{*}$

Progreso humano.- V.

Reglamento del barrio de obreros

Reglamento de "La Bienhechora"

Reglamento del Casino Liceo

Reglamento de la Sección de Beneficencia

Reglamento de la Sección de Instrucción

Reglamento de la Sección de Filarmonía

Reglamento de la Asociación de Dependientes

Reglamento de la Sociedad de Albañiles

Roca Negra (drama)*

La segunda enseñanza en España

El testamento del liberalismo.- Z*

Trozos literarios.- Varios*

Utilidad de las sociedades masónicas.- R. L. V.*

Utilidad de las sociedades masónicas.- L. T. R.

Veinte años de labor (memoria)* 
Verdadera guía de Madrid

ARENAS Y GARCÍA

Estudio de la dualidad y transformación de figuras en el plano

[Estudio analítico elemental de la dualidad y transformación de figuras en el plano / por José Arenas y García. Madrid: [s.n.], 1889 (Manuel Minuesa de los Rios, Imp.). 134 pp., [1] h. de lám. pleg. ; 23 cm]

\section{AUBERT, Carlos}

El coche-cama

[Constan varias obras traducidas de este autor en el CPN, entre ellas Sachá y

Loudmilla; Los últimos bandidos; La Liga; El globo encarnado; El príncipe y

Marfá, todas ellas editadas en Madrid, 1887]

AVECILLA, Pablo de

La conquista del Perú ${ }^{17}$

BACKOUNINE, M.

Dios y el Estado*

[Bakunin, Mijail Aleksandrovich (1814-1876). Dios y el Estado / Miguel Bakounine. R. M., trad.; Álvarez, Ernesto, trad. Madrid: [s.n.], 1900]

BALZAC, H. de

El contrato matrimonial*

[Balzac, Honoré de (1799-1850). El contrato de matrimonio; Un debut en la vida / por H. de Balzac; traducción de Joaquín García Bravo. Barcelona: Luis Tasso, impresor-editor, [s.a.], 1842]

BARREIRO, Francisco L.

El Paraguay

BASTERRA, Félix B.

Sobre ciencia social

BENLLOCH, Francisco J.

La revolución obrera

[La revolución obrera: la Huelga en el $1^{\circ}$ de Mayo / Francisco Jorge Juan Benlloch. Madrid: [s.n.], 1891 (Imp. del Boletín de Obras Públicas). 48 pp.; 16 cm]

\section{BLANCO Y SÁNCHEZ}

Lengua castellana

[Blanco y Sánchez, Rufino (1861-1936). Lengua castellana: método de lectura: primer grado: segunda parte / Rufino Blanco y Sánchez. Madrid: [s. n.], 1899]

17 Aunque figura como Pablo de Arcilla, se trata del autor y de la obra mencionada, es decir: Pablo Alonso de AVECILLA (1810-1880): La Conquista del Perú: novela histórica original. París 1852, 87 págs. 


\section{BLUMENTRITT}

Filipinas

[Consideraciones acerca de la actual situación política de Filipinas / Fernando Blumentritt. Barcelona: [s. n.], 1889 (Imp. Ibérica de Francisco Fossas). 51 pp. ; $22 \mathrm{~cm}]$

BRONSSEUARD, Luis de

Sin dinero

\section{BULLÓN Y FERNÁNDEZ}

Alfonso de Castro y la ciencia penal

[Bullón y Fernández, Eloy (1879-1957). Alfonso de Castro y la ciencia penal.

Madrid: [s. n.], 1900 (Imp. de los Hijos de M. G. Hernández). 138 pp. ; 19 cm]

BUSTILLO, Eduardo

Cosas de la vida

[Bustillo, Eduardo (1836-1908). Cosas de la vida: cuentos y novelitas. Madrid:

[s. n.], 1899 (Imprenta de los Hijos de M. G. Hernández). VIII, 267 pp. ; 19 cm]

BUYLLA, A.

El alcoholismo y la tuberculosis

El alcoholismo

[Álvarez-Buylla y González Alegre, Arturo. El alcoholismo y la tuberculosis:

cartilla de higiene social / A. Buylla. Oviedo: [s. n.], 1902 (La Comercial). 60 pp.; $20 \mathrm{~cm}$. Biblioteca de Higiene Popular]

CABRERA, J.

Por una Julia

CALCAGNO, F.

Zamella*18

CAMPOAMOR, R.

Poesías escogidas*

CANO, Leopoldo

La pasionaria

[Cano y Masas, Leopoldo. La pasionaria: drama en tres actos y en verso / original de Leopoldo Cano y Masas. Madrid: [s. n.], 1884 (M. P. Montoya y Compañía). 148 pp. ; $19 \mathrm{~cm}]$.

CARRILLO, Álvaro

Esposa, virgen y mártir

18 “Zanella" (edición del 6 de septiembre de 1902, p. 4). 


\section{CARRILLO DE ALBORNOZ}

Romancero del Quijote

[Romancero de El ingenioso hidalgo don Quijote de la Mancha: sacado de la obra inmortal de Miguel de Cervantes Saavedra / por su admirador entusiasta Maximino Carrillo de Albornoz. Madrid: [s.n.], 1890 (José Góngora y Álvarez). 2 vols.; 17 cm. T. I (503 pp.) - T. II (631 pp.)]

CASTELAR, Emilio

Historia del descubrimiento de América

Historia de Nerón

CASTELLANOS:

Retórica y poética*

CASTRO Y SERRANO, J. de

La novela de Egipto

[Castro y Serrano, José de (1829-1896). La novela del Egipto: viaje imaginario a la apertura del Canal de Suez... en seis jornadas / Madrid: [s. n.], 1870 (Imp. de T. Fortanet). 365 pp.; $20 \mathrm{~cm}$ ]

CERVANTES, Miguel

El ingenioso hidalgo Don Quijote de la Mancha

\section{COLMEIRO}

Los restos de Colón

[Informe de la Real Academia de la Historia al gobierno de S.M. sobre el supuesto hallazgo de los verdaderos restos de Cristóbal Colón en la iglesia Catedral de Santo Domingo / por Manuel Colmeiro. Madrid: [s. n.], 1878]

\section{CONDORCET}

Vida de Voltaire*

\section{DEMÓFILO}

La redención

D'ENNERY, A.

El príncipe de Moria

[Ennery, Adolphe d‘ (1811-1899). El príncipe de Moria / por Adolphe d'Ennery; versión española de Ricardo de Hinojosa. La Coruña: [s.n.], 1897 (Establecimiento Tipográfico de La Voz de Galicia). 251 pp.; 19 cm]

DICENTA, Joaquín

Visto y vivido

Crónicas 
Una mujer de mundo

Juan José

\section{DOLKOWSKY}

La cooperativa obrera

DUGAST

Leyes sociales

DUMAS, Alejandro

Escenas revolucionarias

EÇA DE QUEIROZ ${ }^{19}$

La reliquia

ECHEGARAY, José

Mariana

Vida alegre y muerte triste

La muerte en los labios

ENNES, A.

Os lazaristas*

ESCOSURA, Patricio de la

Memoria sobre Filipinas y Joló

[Memoria sobre Filipinas y Joló / redactada en 1863 y 1864 por Patricio de la Escosura; publicase ahora por primera vez, ilustrada con un mapa y precedida de un prólogo de Francisco Cañamaque. Madrid: Librería de los señores Simón y Osler, 1882 (Imprenta de Manuel G. Hernández). XL, 447 pp., [1] h. de map. pleg. : ils.; $20 \mathrm{~cm}]$

FABIÉ

Organización y costumbres de las Vascongadas

[Fabié, Antonio María (1832-1899). Estudio sobre la organización y costumbres del país vascongado: con ocasión del examen de las obras de los Sres. Echegaray, Labairu, etc. Madrid: [s. n.], 1896 (Establecimiento tipográfico de Fortanet). XV, 218 pp.; $24 \mathrm{~cm}]$

FAURE, Sebastián

El dolor universal (2 tomos)*

[El dolor universal / Sebastian Faure. Valencia: F. Sempere, [s.a.] (El Pueblo). 2 vols. (210; 233 pp.); $19 \mathrm{~cm}$, hacia 1899]

19 José María Eça de Queiros (o Queiroz), 1845-1900. Está considerado el máximo representante del realismo luso del XIX. 


\section{FERNÁNDEZ GONZÁLEZ, M.}

La mancha de sangre

[La mancha de sangre / novela original por Manuel Fernández y González, Madrid: Imprenta de Fernando Gaspar, editor, 1858. 354, [2] pp., [5] h. de grab.: il.; $23 \mathrm{~cm}]$

\section{FERNÁNDEZ MATEOS, Julio}

Juana la Papisa*

[Juana la Papisa: contestación a un articulista papisero de Santander / por Francisco Mateos Gago y Fernández. Sevilla: imp. y lib. de los Sres. D. A. Izquierdo y Sobrino, 1878. 252 pp.; $19 \mathrm{~cm}]$

FLAMMARION, C.

El fin del mundo*

Curiosidades sidéreas*

FRAGUEIRO, Rafael

Grandeza de mujer ${ }^{20}$

FRANCE, Anatole

La cortesana de Alejandría

[France, Anatole (1844-1924). La Cortesana de Alejandría: (Tais); traducción de Roberto Robert (hijo). Valencia: F. Sempere, [h. 1900]. 232 pp.; 19 cm]

GALLAND, A.

Las mil y una noches*

GALLEGO, Tesifonte

La insurrección cubana

[La insurrección cubana: crónicas de la campaña / Tesifonte Gallego García.

Madrid: [s. n.], 1897 (Imprenta Central de los Ferrocarriles)]

GALLOIS, L.

Historia de la Inquisición*

[Gallois, Léonard Charles André (1789-1851). Historia general de la Inquisición / escrita en francés por Leonardo Gallois; versión castellana de Francisco Nacente. Barcelona: Administración, Ronda del Norte; Madrid: Librería de San Martín, 1869-1870. 1 vol. (230; 216 pp.); $18 \mathrm{~cm}$. Cada tomo con port. y pag propias]

\section{GARCÍA ALIX}

Reorganización de la enseñanza

[García Alix, Antonio (1852-1911), ed. lit. Disposiciones dictadas para la reorganización de la enseñanza: 26 abril a 30 septiembre de 1900 / por Don Antonio

20 Uno de los títulos de la "Biblioteca del Hogar", editada en Buenos Aires. 
García Alix. Madrid: [sn.], 1900 (Imprenta del Colegio Nacional de Sordomudos y de Ciegos). LXIII, 399 pp.; 24 cm]

G. DE CABALLOS, Carlos

El $1^{\circ}$ de mayo

\section{GARCÍA GUTIÉRREZ}

Simón Bocanegra

[García Gutiérrez, Antonio (1813-1884). Simón Bocanegra: drama en cuatro actos precedido de un prólogo / por Antonio García Gutiérrez. Madrid: Manuel Pedro Delgado, 1856 (Imprenta de Cipriano López). 111 pp. ; 19 cm]

\section{GARCÍA DE LA RIEGA}

\section{La gallega}

[García de La Riega, Celso (1844-1914). La Gallega, nave capitana de Colón en el primer viaje de descubrimientos: estudio histórico / por Celso García de la Riega. Pontevedra: [sn.], 1897 (Imp. de la Viuda de J. A. Antúnez). IV, 199 pp. ; $21 \mathrm{~cm}]$

\section{GARRIDO, F.}

Historia de las sociedades obreras*

[Garrido, Fernando (1821-1883). La cooperación: estudio teórico-práctico sobre las sociedades cooperativas de consumo y de producción en Inglaterra y otros países y especialmente en Cataluña / por Fernando Garrido. Madrid: [sn.], 1882 (Imprenta de Juan Iniesta). 127 pp.; $15 \mathrm{~cm}$ ]

\section{GIL MAESTRE}

Los problemas del trabajo

[Los problemas del trabajo y el socialismo / por Manuel Gil Maestre. Barcelona: [sn.], 1897 (Tip. de Luis Tasso). 209 pp. ; 18 cm]

\section{GORKI, Máximo}

Los tres

Los ex-hombres

Los vagabundos

\section{GRANDEAU, L.}

Los cultivos de primavera

[Grandeau, Louis Nicolas. Los cultivos de primavera y el nitrato de sosa / por L. Grandeau; traducido y comentado por La Agricultura Española. Valencia: La Agricultura Española, 1902 (Francisco Vives Mora). 45 págs.; $15 \mathrm{~cm}$ ] 
GRAVE, Juan

Socialismo y anarquismo

Las aventuras de Nono

GUARDÓN, Federico

El martirio del amor

GUILLERMENT, L. F.

¡Notre divise!*

GUTIÉRREZ, Francisco A.

La reforma postal*

[La reforma postal en España: proyectos definitivos que la constituyen / por Francisco de Asís Gutiérrez; apéndice, El futuro edificio para correos. Madrid: [sn.], 1900 (Establecimiento tipográfico de Fortanet, impresor de la Real Academia de la Historia). XIV, 224 págs., [2] lam. ; $22 \mathrm{~cm}$ ]

HERNÁNDEZ, José Manuel

Carta a Crespo

HUESCA

Zajara

[Zajara/ Federico Huesca. Madrid: [sn.], 1889 (Tipografía de los huérfanos). 7 vols., 326 págs .: il.; $19 \mathrm{~cm}]$

HUGO, Víctor:

Los miserables*

Cristo en el Vaticano*

La enseñanza clerical*

Voltaire*

Los trabajadores del mar

Han de Islandia

El hombre que ríe

Bug-Jargal

El último día de un reo

Claudio Gueux

Nuestra Señora de París

El noventa y tres

Napoleón el Pequeño

Historia de un crimen

Cromwell

Hernani

Marión de Lorme

El rey se divierte

Lucrecia Borgia 
María Tudor

Ángelo

La esmeralda

Ruy Blas

Los burgraves

Odas y baladas

Los orientales

Hojas de otoño

Cantos del crepúsculo

Voces interiores

Rayos y sombras

Los castigos

Las contemplaciones

Las canciones de las calles y de los bosques

El arte de ser abuelo

El año terrible

La leyenda de los siglos

El Papa

La piedad suprema

Religiones y religión

El asno

París

Los cuatro vientos del espíritu

Memorias

Inés de Castro

El primitivo Bug-Jargal

Artículos críticos

HUMBOLDT, G. de

Los primitivos habitantes de España

[Humboldt, Karl Wilhelm, Freiherr von (1767-1835). Los primitivos habitantes de España: investigaciones con el auxilio de la lengua vasca / por G. de Humboldt; traducción de Ramón Ortega y Frías. Madrid: lib. de José Anlló, 1879 (Imprenta, estereotipia y Galvanoplastia de Aribau y Ca). VIII, 224 págs.; 19 cm. Tít. original: „Prüfung der Untersuchunge über die Urbewohner Hispaniens vermittelst der Vaskischen Sprache"]

\section{HUMMUS}

A la memoria de Lincoln

[Los mártires de la república : cuadros históricos de los sufrimientos, de las penalidades, de los martirios de todos los grandes apóstoles de la idea republicana: episodios dramáticos é interesantes, de las existencias de Cuello, Terradas, Lincoln, Kossuth, Mazzini, Sixito Cámara y tantos otros, ilustres víctimas de la tiranía: historia de la republica en general sintetizada en sus mártires / páginas trazadas por una sociedad de escritores republicanos. Barcelona: Biblioteca Escogida, 1873 
(Imprenta de El Porvenir de la viuda Bassas, á cargo de J. Medina). 2 vols. (624 págs., [9] h. de lám.; 526 págs., [9] h. de lám.); 24 cm]

\section{ILLENATNOM}

Nuestras convicciones

\section{JACQUINET, Clemencia}

Historia universal

[Compendio de historia universal / Clemecia Jacquinet. Barcelona: Escuela Moderna, 1901-1902 $20 \mathrm{~cm}$. Serie: Escuela Moderna. Incluye: Vol. I: "Tiempos prehistóricos al Imperio Romana” (223 págs.) - Vol. II: „La edad Media” (298 págs.)]

JEVONS, W. Stanley

Nociones de lógica*

Lógica

[Jevons, W. Stanley. Nociones de lógica / W. Stanley Jevons. Nueva York:

D. Appleton y Compañía, 1887. 180 págs.; $16 \mathrm{~cm}]$

\section{JUSNÉ}

Tablas para comprobación de fechas

\section{KARDEC, Allan}

Revelación espiritista*

[Kardec, Allan (1803-1869). Espiritismo experimental ó El libro de los médiums: guía de los médiums y de los evocadores, contiene la enseñanza especial de los espíritus sobre la teoría de todos los géneros de manifestación, los medios de comunicar con el mundo invisible, el desarrollo de la mediumnidad y las dificultades y escollos que pueden experimentarse en la práctica del espiritismo / continuación de el libro de los espíritus por Allan Kardec. San Martín de Provensals: [s. n.], 1887 (imprenta de Juan Torrens y Coral). 161, [3] págs.; 24 cm]

[¿Que es el espiritismo?: introducción al conocimiento del mundo invisible por las manifestaciones de los espíritus / por Allan Kardec. San Martín de Provensals: [s. n.], 1888 (Establ. Tip. de Juan Torrents y Coral), 65 págs.; 24 cm. En la parte superior de la port.: Revelación III.-Sección doctrinal.- Obras recopiladas por A. K.]

KROPOTKINE, P. $^{21}$

La conquista del pan*

El espíritu revolucionario*

El salario*22

Palabras de un rebelde

21 Piotr Alekséyevich Kropotkin (1842-1921), pensador político ruso, geógrafo y naturalista. Uno de los principales teóricos del anarquismo y fundador de la escuela anarco-comunista.

22 El Asalariado (edición del 6 de septiembre de 1902, 4 págs.). 
KUBLY, E.

Los dioses caídos

[Los dioses caídos / Enrique Kubly. Lisboa : [s.n.], 1884 (Typ. de Christovão

Augusto Rodrigues). 27 págs.; $22 \mathrm{~cm}$ ]

LARA Y PEDRAJAS, A. de

Don Antonio Cánovas del Castillo

[D. Antonio Canovas del Castillo / estudio crítico por Antonio de Lara y Pedrajas.

Madrid: [sn.], 1901 (Imprenta de los hijos de M. G. Hernández) [4], 280 págs.;

$22 \mathrm{~cm}]$

LAURENT, F.

La mendicidad y la Iglesia*

LLEDÓ, José E.

La enseñanza de la filosofía*

[La enseñanza oficial de la filosofía en España desde el año 1857 / José España

Lledó. Madrid: [s. n.], 1890 (Hernando y Cía.). 28 págs.; 18 cm]

MACÍAS, José M.

Clavijero*

MADARIAGA Y SUÁREZ

Código de Justicia de la Marina

[Código de justicia criminal de la Marina de Guerra y Mercante / por Juan de Madariaga y Suárez. Madrid: [s. n.], 1898 (Imprenta del Ministerio de Marina, 1899). 454 págs. ; $23 \mathrm{~cm}]$

MALATESTA, E. ${ }^{23}$

Entre campesinos

[Entre campesinos / Enrique Malatesta; traducción J. Prat. [España]: Revista Blanca, [s. a.] 32 págs.; $19 \mathrm{~cm}$ ]

MALATO, Carlos

Filosofía del anarquismo

[Filosofía del anarquismo / Carlos Malato; traducción de Félix Azzati. Valencia:

F. Sempere y Ca , [188-?], o 1902. 188 págs.; 19 cm]

MAZZONI, Ana M.

A las hijas del pueblo*

23 Errico Malatesta (1853-1932), pensador político italiano que está considerado uno de los clásicos del anarquismo. 
MÉNDEZ, Cátule

Para leer en la cama

MEREJKOWSKY, Dimitri

La muerte de los dioses

[La muerte de los dioses: (la novela de Juliano el Apóstata) / por Dmitry de Merejkowsky; única traducción completa por Demetrio Zorrilla. Madrid: La España Moderna, [c. 1900] (establecimiento tipográfico de Idamor Moreno). 223 págs.; $22 \mathrm{~cm}]$

[La muerte de los dioses: (la novela de Juliano el Apóstata) / Dmitry de Mérejkowsky; traducción y prólogo de Luis Morote. Valencia: Francisco Sempere, editor, 1901 (Imprenta del Pueblo). 2 vols.; $19 \mathrm{~cm}$ ]

\section{MESA DE LA PEÑA}

En la guerra y en la paz

[España: notas político-militares / por Rafael Mesa de la Peña. Madrid: [sn], 1899 (Imp. de la Correspondencia Militar). Precede al tit.: En la guerra; en La paz. 65, [2] págs.; $22 \mathrm{~cm}$ ]

MIRABEAU, Octavio

Sebastián Roch

MONFORT, Manuel

El golfo de Guinea

[Monfort, Manuel. La Guinea Española / por el abate Mendo (M. M. P.). Montevideo: [sn], 1901 (Imp. "El Siglo Ilustrado"). El abate Mendo es seud. de Manuel Monfort. T. I (381, VI, II págs.); vol. 1; 23 cm]

MONTEPIN, Xavier de ${ }^{24}$

Perdita

La señorita de compañía

El misterio de Pontarmé

La Quinta de las Rosas

El consejo de los doce

La virgen viuda

La confesión de un bohemio

Fatalidad

La gitana

Los amores de Oliver

24 Xavier Henri Aymon Perrin, conde de Montépin (1823-1902), novelista francés, autor de folletines y dramas populares que le granjearon fama internacional. Autor de uno de los folletines más vendidos del siglo XIX, La Porteuse de pain (de 1884 a 1889), que fue adaptado al teatro y, posteriormente, al cine y a la televisión. Se le multó por plagio en alguna que otra ocasión. 
La cartomántica

La hija del lujo

El secreto del Titán

La madrastra

Un capitán de húsares

El secreto de la condesa

El marido de Elena

Luciano Gobert

El médico de las locas

La casa de salud

Cuatro mujeres

MORA, Juan de Dios

Pelayo*

[Mora, Juan de Dios de (1827-1884). Pelayo: novela histórica / original de Juan de Dios de Mora. Madrid: Miguel Prats, 1867 (Impr. de C. González). 873 págs., [14] h. de lám.: ils.; 24 cm]

NAKENS, José ${ }^{25}$

Los crímenes del carlismo ${ }^{26}$

[Los horrores del absolutismo / José Nákens. Valencia, Madrid: F. Sempere y

Compañía, [s.d.]. 321 págs.; $19 \mathrm{~cm}$ ]

NAVARRETE, José

María de los Ángeles

[María de los Ángeles / por José Navarrete. Coruña: [sn], 1883 (Estab. tip. de la Voz de Galicia). 297 págs.; $20 \mathrm{~cm}$ ]

ORTS RAMOS, Tomás

La alegría de amar

OYNELOS, R.

Leyes sociales

PALACIO VALDÉS, Armando

Solo

[Palacio Valdés, Armando (1853-1938). Solo: novela / A. Palacio Valdés; ilustraciones de R. Paris. Madrid: B. Rodríguez Serra, 1899]

25 José Nakens Pérez (1841-1926), periodista, escritor y político republicano español. Redactor de $E l$ Globo (a partir de 1876), editor de El Motín (a partir de su fundación en 1881), y redactor de Vida Nueva (a partir de 1898). Propuso la creación de la Asamblea Republicana, que se reunió a partir de 1903.

26 "Donados por Manuel S. Espinosa". 
PANIAGUA, M.

Veinte años de labor

PATRONI, Adrián

A los indiferentes*

PENIRERNI

El puñado de sal

PÉREZ CARRASCO, J.

El burgués

PÉREZ DE MOLINA, M.

Del pauperismo

[Del pauperismo, sus causas y remedios / por Manuel Pérez de Molina. Madrid:

[sn], 1868 (Imprenta de M. Tello). VII, 354 págs.; $20 \mathrm{~cm}$ ]

PÉREZ MINGUEZ, Fidel

Leyes sociales*

[Pérez R. Mínguez, Fidel. Revisión del Código Civil: proyecto de reformas / por

D. Fidel Pérez R. Mínguez. Madrid: [sn], 1899 (Tipo-Litografía y Encuadernación de L. Miñón). 53 págs.; $21 \mathrm{~cm}]$

PI ARSUAGA, Francisco

El Cid Campeador

[El Cid Campeador: novela histórica / Francisco Pi y Arsuaga. Barcelona: Antonio López, [s. a.], h. 1899, 192 págs.: il.; 15 cm]

PI Y MARGALL, Francisco

El partido federal

[La federación: discurso pronunciado ante el tribunal de imprenta en defensa del periódico federalista La Unión / por Francisco Pi y Margall; precedidos de una noticia biográfica del autor por Pablo Correa y Zafrilla. Madrid: Librería de Francisco Iravedra, 1881. XXVI, 222 págs.; $18 \mathrm{~cm}$ ]

PIGAULT LEBRUN

El citador

[Pigault-Lebrun (1753-1835). El citador / obra escrita en francés por Pigault

Lebrun; traducida por Antonio Revenga. Valencia: [sn], 1882 (Imp. de La Nueva Alianza). IX, 271 págs.; $16 \mathrm{~cm}]$

PONS, Adolfo

Cánovas del Castillo

[Cánovas del Castillo / por Adolfo Pons y Umbert. [S. 1.: sn, s. a.] (Madrid: Imp. de M. G. Hernández, 1901). 625 págs.; $23 \mathrm{~cm}$ ] 
PUIMAYOR Y BUDAR

Vida del Beato Gaspar de Bono

[Noticias biográficas del beato Gaspar de Bono, sacerdote del Sagrado Orden de los Mínimos... / extractadas de la historia de su vida escrita por Félix Puimayor y Budar. Valencia: [s. n], 1886 (Imp. de M. Manáut). 39 págs.; 21 cm]

\author{
RAGON, J. M..$^{27}$ \\ El doble triángulo
}

\title{
RAMOS CARRIÓN, M.
}

Zaragüeta

Coro de señoras

La gallina ciega

[Ramos Carrión, Miguel (1848-1915). Zaragüeta: comedia en dos actos y en prosa / original de Miguel Ramos Carrión y Vital Aza. Madrid: [sn], 1895

(R. Velasco, imp.). 71 págs.; $20 \mathrm{~cm}]$

[Coro de señoras: pasillo cómico-lírico en un acto y en prosa / original de Ramos Carrión, Pina Domínguez y Vital Aza; música del maestro Nieto. Madrid: [sn], 1892 (R. Velasco, imp.). 38 págs.; $20 \mathrm{~cm}]$

27 Jean-Marie Ragon de Bettignies (1781-1862), nació en Bray-sur-Seine. Su padre ejercía las funciones de notario. Se inició en la masonería en 1804, en Brujas, donde desempeñaba funciones burocráticas para la administración imperial. Miembro del Grande Oriente de Francia, fundó y presidió la célebre logia parisina "Les Vrais Amis" (Los Verdaderos Amigos), que posteriormente pasó a llamarse "Les Trinosophes" (Los Trinósofos). Formó parte también de su capítulo y del Areópago del taller. Según se ha señalado, sus contemporáneos le consideraron el francmasón más sabio del siglo XIX, y es cierto que publicó diversas obras que tuvieron una gran influencia, tanto en Francia como en el exterior. Entre sus textos destacan: La Messe et ses Mystères, L'Orthodoxie maçonnique, La Maçonnerie occulte y Le Cours philosophique et interprétatif des initiatinos anciennes et modernes. Merece, asimismo, especial atención la serie de rituales masónicos que se sigue reeditando en Francia y en otros países. De la que existen traducciones al español desde el propio siglo XIX. Fue, también, el editor de Hermes, la primera revista masónica de Francia. Según la tercera edición del Dictionnaire de la Franc-maçonnerie de Daniel Ligou (PUF, París, 1991: 993), falleció en 1866. En esta obra se indica, además, que su temprana iniciación tuvo lugar en la logia Les Amis du Nord. Se precisa, asimismo, que la logia parisina de Los Verdaderos Amigos fue fundada por el biografiado el $1^{\circ}$ de octubre de 1814. Viajó a América, en torno a 1820, lo que efectivamente influyó sobre su posterior carrera masónica. Frau y Arús apuntan, por su lado, que se le consideró uno de los masones más distinguidos de su época, así como uno de los escritores más notables de la Orden. Les Trinosophes llegó a ser una de las logias más importantes de la capital francesa. Viajó, en efecto, por diversos lugares "procurando acrecentar el caudal de sus grandes conocimientos masónicos y enriquecer con valiosas adquisiciones la preciosa colección de rituales", de los que llegó a reunir más de cuatrocientos. En otro orden de cosas, tomó parte muy activa en los trabajos de reforma que llevó a cabo el Grande Oriente francés, "del que fue siempre acérrimo partidario, y muy especialmente en los que" se realizaron para la introducción y propagación en Francia del Rito de Misraim. 
[La gallina ciega: zarzuela cómica en dos actos y en prosa / letra de Miguel Ramos Carrión; música del maestro Fernández Caballero. Madrid: [sn], 1873 (Imp. de José Rodríguez). 54 págs.; $19 \mathrm{~cm}$ ]

\title{
RAMOS SARMIENTO
}

La gran araña

RECLÚS, E. ${ }^{28}$

Evolución y revolución*

La montaña

[Reclús, Elisée (1830-1905). Evolución y revolución / Elíseo Reclus; traducción de A. López Rodrigo. Valencia: F. Sempere, [s. a.], h. 1900, (Imp. de El Pueblo). 196 págs.]

[La montaña / Eliseo Reclus; prólogo de Pedro Kropotkine; traducción de A. López Rodrigo. Valencia: Ediciones Estudios, [s. a.]. 159 págs.; $19 \mathrm{~cm}$ ]

\section{RECUR}

Filipinas y el comercio nacional

[Filipinas: el comercio nacional y el desestanco del tabaco / por Carlos Recur. Madrid: [sn], 1881 (Imprenta de Fortanet). 29 págs.; $23 \mathrm{~cm}$ ]

\author{
RENAN, Ernesto $^{29}$ \\ Los Apóstoles \\ Vida de Jesús \\ Estudios religiosos
}

RETES, Francisco Luis de

Otello

L'Hereu

[Retes, Francisco Luis de (1822-1901); Shakespeare, William (1564-1616).

Othello. Otelo, el moro de Venecia: drama trágico en cuatro actos, en verso, escrito con presencia de la obra de W. Shakespeare / por Francisco Luis de Retes. Madrid: [s. n], 1868 (Imprenta de José Rodríguez). 98 págs.; 20 cm]

28 Élisée Reclus (Jacques Élisée Reclus), 1830-1905, geógrafo francés y miembro (anarquista) de la I Internacional. Son famosos sus tratados de geografía humana y de geografía económica.

29 El historiador francés Joseph Ernest Renan (1823-1892), contribuyó a la búsqueda del Jesús histórico con su obra La vida de Jesús, que se publicó en París (1863), y que suscitó un gran escándalo en su tiempo, ya que calificaba a Jesús como "anarquista". También es relevante y actual su visión acerca de la nación, que deja en un segundo plano cuestiones como la religión, la raza, el idioma, la cultura y el territorio, y afirma que, en particular, se trata de una "creencia" (Joan BESTARD, Parentesco y modernidad, 1998, p. 29). Fue miembro de la Academia Francesa y administrador del Collège de France. 
[L'hereu: drama en tres actos y en verso / original de Francisco Luis de Retes y Francisco Pérez Echevarría. Madrid: [sn], 1874 (Imp. de José Rodríguez).

87 págs.; $19 \mathrm{~cm}]$

REY, M.

¿Dónde está Dios?

ROSCOE

Nociones de Química*

Nociones de Física*

[Nociones de química / por H. E. Roscoe. Nueva York: D. Appleton y compañía, 1889. 140 págs.; $16 \mathrm{~cm}]$

RUEDA, Salvador

La gitana

[La gitana: (idilio en la sierra): novela andaluza / Salvador Rueda. Madrid: [sn], 1892 (Imp. de Luis Aguado). 264 págs.; $18 \mathrm{~cm}]$

SALCEDO RUIZ, Ángel

El libro de Villada

[El libro de Villada: monografía histórica de esta villa y noticia biográfica de sus

hijos más ilustres / por Ángel Salcedo y Ruiz... Madrid: Ayuntamiento de Villada, [s. a.] (1901 imp.). 252 págs.: ils.; $20 \mathrm{~cm}$ ]

SALES, Francisco de

Costumbres venezolanas*

[Costumbres venezolanas: colección de artículos / por Francisco de Sales Pérez, hijo; ilustrados con laminas originales del pintor venezolano Arturo Michelena. New York: Imprenta y Librería de N. Ponce de León, 1877. 186, [2] págs., [10] h. de grab.; $21 \mathrm{~cm}]$

\section{SCHMID}

Cuentos*

[Schmid, Christoph von (1768-1854). Cuentos de Schmid. Nueva ed. / ilustrada por G. Staal con muchas y hermosas láminas. Paris: Libr. de Garnier Hermanos, 1866. 544 págs.: ils.; $21 \mathrm{~cm}]$

\section{SCHOPENHAUER}

La vida, el amor y la muerte

[Schopenhauer, Arthur (1788-1860). La vida, el amor y la muerte / Arturo Schopenhauer; traducción de Tomás Orts Ramos y Climent. Barcelona: [s. n.], 1901 (Pertierra, Bartolí y Ureña). 240 págs.; 19 cm] 
SERRANO, Francisco

La justicia de Dios

[La justicia de Dios: drama en un acto, en prosa y verso y tres cuadros / original de Francisco Serrano Sempere. Alicante: [s. n., s. a.], c. 1899. (Imprenta Sirvent y Sánchez). 33 págs.; $20 \mathrm{~cm}$ ]

SIENKIEWICH, Enrique

Misterio del amor

Por el pan

SILES, José de

La pícara Cornelia*

SITTA, P.

La población de la Argentina

SOLDEVILLA, Fernando

El año político ${ }^{30}$

SUÉ, Eugenio

La vanidad de una madre

[Sue, Eugène (1804-1857). La vanidad de una madre y la perdición de una hija / por Eugenio Sue; vertida al castellano por F. Figueras. Barcelona: Juan Pons ; Habana [sic]: José Montaner ; Matanzas : José Bataller, 1866 (Impr. Hispana de Vicente Castaños). 802 págs., [10] h. de lám.: ils.; 26 cm]

TAMAYO, Manuel ${ }^{31}$

Un drama nuevo

Hija y madre

TOLSTOI, León

Resurrección

La verdadera vida

El hombre libre

La aurora social

Los Evangelios

El canto del cisne

El príncipe Neklindoy ${ }^{32}$

Amo y criado

30 Figuran publicados los años políticos de 1895 a 1901 .

31 Manuel Tamayo y Baus (1829-1898). Su obra más famosa fue Un drama nuevo (representado el 4 de mayo de 1867), inspirado en el teatro de Shakespeare. Secretario perpetuo de la Real Academia Española (1874) y director de la Biblioteca Nacional (1884) y del cuerpo de archiveros. Compuso más de medio centenar de piezas dramáticas.

32 De las memorias del príncipe D. Nejliúdov. 
Dos aventuras

Imitaciones

VAL, Luis de

Los pobres de levita

[Val, Luis de (n. 1867). El Dinero, ó, Los pobres de levita / su autor: Luis de Val; ilustraciones de A. Seriñá. Barcelona: Centro Editorial Artístico de Miguel Seguí, [s. a.], 1896 según Palau]

VALBUENA, A.

Fe de erratas*

[Valbuena, Antonio de (1844-1929). Fe de erratas del nuevo Diccionario de la Academia / por D. Antonio de Valbuena (Miguel de Escalada). Madrid: La España Editorial, 1891 (Imp. de J. Cruzado). 4 vols.; 19 cm]

VALERA, Juan

Asclepigenia

[Valera, Juan (1824-1905). Asclepigenia / Juan Valera. Madrid: [s. n.], 1900 (Imprenta y Fotograbado de E. Rojas). 94 págs.; 14 cm]

\section{VALVERDE Y ÁLVAREZ}

Cartilla de dibujo topográfico

[Cartilla elemental de dibujo topográfico / por Emilio Valverde y Álvarez. Madrid: Imprenta de Fernando Cao y Domingo de Val, 1887 [50] págs.: ils.; $18 \mathrm{~cm}$ ]

\section{VÁZQUEZ TABOADA, $M$.}

El sitio de Zaragoza*

[El Sitio de Zaragoza/ novela histórica original de D. Manuel Vázquez Taboada. Madrid: [s. n.], 1867 (Imp. de la Galería Literaria). 965 págs. [15] h. de lams. ; $24 \mathrm{~cm}]$

VERNE, Julio

De Glasgow a Charleston

Los ingleses en el Polo Norte

El desierto de hielo

Claudio Bombarnac

Los hijos del capitán Grant

VIDAL, J. R.

Los parrales de Almería

VOLTAIRE

Cándido*

Zadig*

Micromegas* 
La princesa de Babilonia*

Cartas de Amabed*

Los oídos del conde*

El ingenuo*

Viajes del escarmentado*33

Como anda el mundo*

El toro blanco*

Cosi-santa*

Historia de Jeni*

Historia de Pedro el Grande*

Historia del parlamento de París*

Siglo de Luis XIV*

Siglo de Luis $\mathrm{XV}^{*}$

Ensayo sobre las costumbres (en dos tomos)*

ZAMACOIS, Eduardo

Loca de amor

El seductor

Horas crueles

ZOLA, Emilio

Trabajo

Como se muere

\section{Canarias}

ANÓNIMOS

Entre canarios

El Guanche

Inauguración del cable a Tenerife

El Museo Canario

AROZENA, M.

La hija del bosque ${ }^{34}$

Luchas del alma

ARRIBAS, Cipriano de

A través de las Islas Canarias*

BERTHELOT, Sabino

Por la costa de España

33 "Viajes de Escarmentado" en listado publicado el 6 de septiembre 1902, p. 4.

34 Donado por Romualdo Real. 
ESPINOSA DE LOS MONTEROS, M. B., SERVET

Memoria sobre el jesuitismo*

[Memoria presentada por el h. Servet (Miguel B. Espinosa de los Monteros Rodríguez),..., en el concurso mas. Celebrado por la Resp. Log. Cap. Lealtad, $n^{\circ} 78, \ldots$

de Barcelona..., Tenerife, 1879]

ESTÉVANEZ, Nicolás

Calandracas

GONZÁLEZ, Juan María

Apuntes de geografía político-militar [de las islas Canarias]

GONZÁLEZ DÍAZ, Francisco

Comunicación con la Península

MARTÍNEZ, Casto

El primo

MIRANDA, M.

Magnetismo y espiritismo*

OSSUNA, Manuel

La flora de Anaga

PARRILLA, Justo P.

Geografía general

PERERA Y ÁLVAREZ, Guillermo

La princesa Dácil*

PEREYRA, M.

Un cuarto a espadas*

Tipos de mi tierra

PÉREZ GALDÓS, Benito

El 19 de marzo

Mendizábal

El 2 de mayo

Electra

Gerona

Cádiz

Trafalgar

La batalla de Arapiles

Un faccioso más 
PÉREZ DEL TORO

España en el África

PÉREZ ZAMORA

Biografía de Pérez Zamora*

PICAR, Manuel

¡Tiempos mejores!

PIZARROSO, Carlos

Esbozos poéticos

PUERTA, Juan de la

Geografía de Canarias

RODRÍGUEZ, Leoncio ${ }^{35}$

Alma canaria*

RUIZ Y BENÍTEZ DE LUGO, Ricardo

Maravillas históricas

La enciclopedia del año

SERRA, Leandro

Cuarto centenario de la conquista de Canarias

VILLALBA HERVÁS, Miguel

Los partidos políticos

WANGÜEMERT Y POGGIO

Consideraciones sobre Canarias

ZEROLO, Elías

Emancipación de los trabajadores

ZURITA, Amado

La agricultura en Canarias*

(Escrito en español por los autores)

35 Debe tratarse de un cuento o un folleto de pequeño tamaño, ya que la primera edición de los Cuentos canarios de este autor, bajo el seudónimo de Luis Roger, es de 1905. 


\section{BIBLIOGRAFÍA}

BESTARD, Joan, Parentesco y modernidad, Barcelona: Paidós, 1998.

DARNTON, Robert, Edición y subversión. Literatura clandestina en el Antiguo Régimen, Madrid: Turner - Fondo de Cultura Económica, 2003.

GALVÁN FERNÁNDEZ, Francisco, Burgueses y obreros en Canarias: (del S. XIX al XX), La Laguna: Secretariado de Publicaciones, 1986.

GALVÁN FERNÁNDEZ, Francisco - MARTÍNEZ DE AZAGRA, Luis, Trabajos socioeconómicos: Canarias a finales del siglo XIX, Santa Cruz de Tenerife: Benchomo, 1994.

GONZÁLEZ ANTÓN, Javier, "El libro antiguo en Canarias", in: Pedro Manuel Cátedra García y María Luisa López-Vidriero Abello, Separata de: El libro antiguo español: actas del Segundo Coloquio Internacional (Madrid), Salamanca: Universidad de Salamanca, 1992, pp. 241-246.

"Patrimonio bibliográfico" [on-line]. Patrimonio Bibliográfico Español, [consultado 10 de agosto de 2019]. Accesible de: http://catalogos.mecd.es/CCPB/cgi-ccpb/abnetopac/O12444/IDc8f6f80d ?ACC $=101$ ).

PAZ SÁNCHEZ, Manuel de, La biblioteca olvidada: (los libros del Convento Franciscano de Garachico), Santa Cruz de Tenerife: Idea, 2010.

PAZ SÁNCHEZ, Manuel de, "El Jardín de la Virtud (La masonería como una disidencia cristiana del XIX)”, Anuario de Estudios Atlánticos 53, 2007, pp. 299-336.

ROMERO TALLAFIGO, Manuel, De libros, archivos y bibliotecas: venturas y desventuras de la escritura, Las Palmas de Gran Canaria: UNED, 2008.

\section{Breve información sobre los autores \\ Manuel de Paz Sánchez}

Correo electrónico: mdepaz@ull.edu.es

Doctor en Historia con Premio Extraordinario (1982). Catedrático de Historia de América en la Universidad de La Laguna (Tenerife, Islas Canarias. España), desde 1995. Se ha especializado en Historia del Atlántico, Historia de la Masonería e Historia de Cuba. Autor de numerosos libros y artículos, publicados en España y en otros países de Europa y América.

\section{Valeria Aguiar Bobet}

Correo electrónico: vaguiar@uji.es

Doctora en Historia por la Universidad Jaume I de Castellón (enero de 2020). Ha publicado en revistas europeas y americanas como Hispania, Revista de Indias, REHMLAC, así como también los libros: Cuba en el Horizonte (2017); En busca de un nuevo al-Ándalus (2019) y El orientalismo a la vuelta de la esquina (2020). Es codirectora de las colecciones Escuadra y Compás y Cuadernos del Magreb de Ediciones Idea.

\section{Ángel Dámaso Luis León}

Correo electrónico: aluisleo@ull.edu.es

Doctor en Historia por la Universidad de La Laguna (septiembre 2020). Especializado en historia contemporánea de Venezuela y Cuba, codirige la colección Letras de Cuba de Ediciones Idea. Ha publicado artículos en varias revistas europeas y americanas. Ha escrito, entre otros libros, Chávez al poder. Génesis y formación del movimiento bolivariano (2015), Entre la revolución y la utopía (2019) o Viajar en el Telémaco (2020). 